\title{
An empirical note about estimation and forecasting Latin American Forex returns volatility: the role of long memory and random level shifts components
}

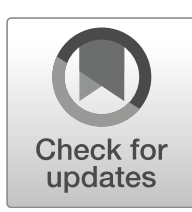

\section{Gabriel Rodríguez ${ }^{1}$ (1) . Junior A. Ojeda Cunya ${ }^{1}$. José Carlos Gonzáles Tanaka ${ }^{1}$}

Received: 29 March 2017 / Accepted: 28 January 2019 / Published online: 26 February 2019

(C) ISEG - Instituto Superior de Economia e Gestão 2019

\begin{abstract}
A set of RLS-type models with ARMA and ARFIMA dynamics is estimated and compared in a forecasting exercise with ARFIMA, GARCH and FIGARCH models. It is an extension of Rodríguez (N Am J Econ Financ 42:393-420, 2017) but using more countries and working with squared returns in the forecasting exercise. The estimation results show: (i) existence of RLS; (ii) measurement errors except in Chile and Colombia. Regarding the fractional parameter, the estimates are quite small indicating the possible absence of long memory with possible exceptions of Chile and Colombia. The forecast exercise using the 10\% MCS of Hansen et al. (Econometrica 79:453-497, 2011) and the ratios of MSFE indicate absence of the RLS-ARFIMA models while RLS-ARMA models are selected. In general, the results of the estimations and forecasts indicate probable absence of long memory or its small magnitude, which would makes this characteristic not only unnecessary but also irrelevant to capture the variations of the low frequencies of the series.
\end{abstract}

Keywords Random Level Shifts · Long memory · Latin American Forex Markets · Volatility · Time Varying Probability · Mean reversion · ARFIMA models ·

GARCH model · FIGARCH model

\footnotetext{
This is a subtantially revised and reduced version of Gonzáles Tanaka and Rodríguez (2016) which circulated under the title "An Empirical Application of a Random Level Shifts Model with Time-Varying Probability and Mean Reversion to the Volatility of Latin-American Forex Markets Returns.” We thank useful comments of Paul Castillo B. (Central Reserve Bank of Peru), Jiawen Xu (Shangai University of Finance and Economics), Zhongjun Qu and Pierre Perron (Boston University), Patricia Lengua Lafosse (UPC), Miguel Ataurima Arellano (PUCP) and participants to the Latin American Meeting of the Econometric Society (Guayaquil, November 8-10, 2018). We also appreciate the helpful and constructive comments from two anonymous referees and the Editor Professor Paulo M. M. Rodrigues who have helped improve and focus the document. Any remaining errors are our responsibility.
}

Gabriel Rodríguez

gabriel.rodriguez@pucp.edu.pe

1 Department of Economics, Pontificia Universidad Católica del Perú, Av. Universitaria 1801, Lima 32, Lima, Perú 